\title{
Correction to: Rapid Identification of Seven Waterborne Exophiala Species by RCA DNA Padlock Probes
}

\author{
M. J. Najafzadeh $\cdot$ V. A. Vicente $\cdot$ Peiying Feng $\cdot$ A. Naseri $\cdot$ Jiufeng Sun \\ A. Rezaei-Matehkolaei - G. S. de Hoog $\mathbb{B}$
}

Published online: 14 May 2018

(C) Springer Science+Business Media B.V., part of Springer Nature 2018

Correction to: Mycopathologia (2018)

https://doi.org/10.1007/s11046-018-0256-7

The Editorial Office of Mycopathologia reports that several paragraphs of Najafzadeh et al. were transcribed with only minor edits from previously published material by Najafzadeh M. J. Proper citation of

The original article can be found online at https:// doi.org/10.1007/s11046-018-0256-7.

M. J. Najafzadeh · A. Naseri

Department of Parasitology and Mycology, Faculty of

Medicine, Mashhad University of Medical Sciences,

Mashhad, Iran

e-mail: najafzadehmj@mums.ac.ir

\section{J. Najafzadeh}

Cancer Molecular Pathology Research Center, Mashhad

University of Medical Sciences, Mashhad, Iran

\section{A. Vicente · G. S. de Hoog ( $\square)$}

Microbiology, Parasitology and Pathology Post-

Graduation Program, Department of Basic Pathology,

Federal University of Paraná, Curitiba, Brazil

e-mail: s.hoog@westerdijkinstitute.nl

\section{P. Feng}

Third Affiliated Hospital, Sun Yat-sen University,

Guangzhou, China the original source was inadvertently omitted, and the paper should have included the citation of $[\mathrm{Na}-$ jafzadeh, M. J. (2011). Biodiversity, pathogenicity, antifungal susceptibility and rapid identification of Fonsecaea and relatives. Ede: Ponsen\&Looijen b.v.].

Mycopathologia is a member of the Committee on Publication Ethics and therefore ensures that original sources of information are properly cited in all of our publications.

J. Sun

Guangdong Provincial Institute of Public Health, Guangdong Provincial Center for Disease Control and Prevention, Guangzhou, China
A. Rezaei-Matehkolaei
Department of Medical Mycology, School of Medicine, Ahvaz Jundishapur University of Medical Sciences,
Ahvaz, Iran
G. S. de Hoog
Westerdijk Fungal Biodiversity Institute, Utrecht, The Netherlands
G. S. de Hoog
Center of Expertise in Mycology Radboudumc/Canisius Wilhelmina Hospital, Nijmegen, The Netherlands 